\title{
Bupropion and Citalopram in the APP23 Mouse Model of Alzheimer's Disease: A Study in a Dry-Land Maze
}

\author{
Katharina L. Neumeister ${ }^{1}$ and Matthias W. Riepe ${ }^{1,2}$ \\ ${ }^{1}$ Division of Mental Health \& Old Age Psychiatry, Psychiatry II, Ulm University, 89312 Günzburg, Germany \\ ${ }^{2}$ Department of Geriatrics \& Old Age Psychiatry, Psychiatry II, Ulm University, Ludwig-Heilmeyer-Straße 2, \\ 89312 Günzburg, Germany
}

Correspondence should be addressed to Matthias W. Riepe, matthias.riepe@uni-ulm.de

Received 29 March 2012; Accepted 3 September 2012

Academic Editor: Francesco Panza

Copyright $\odot 2012$ K. L. Neumeister and M. W. Riepe. This is an open access article distributed under the Creative Commons Attribution License, which permits unrestricted use, distribution, and reproduction in any medium, provided the original work is properly cited.

Background. Incipient Alzheimer's disease is often disguised as depressive disorder. Over the course of AD, depressive symptoms are even more frequent. Hence, treatment with antidepressants is common in AD. It was the goal of the present study to assess whether two common antidepressants with different mechanisms of action affect spatial learning in a transgenic animal model of Alzheimer's disease. Methods. We assessed spatial memory of male wild-type and B6C3-Tg(APPswe,PSEN1dE9)85Dbo (APP23) transgenic animals in a complex dry-land maze. Animals were treated with citalopram $(10 \mathrm{mg} / \mathrm{kg})$ and bupropion $(20 \mathrm{mg} / \mathrm{kg})$. Results. Moving and resting time until finding the goal zone decreased in 4.5-month-old sham-treated wild-type animals and, to a lesser extent, in APP23 animals. Compared with sham-treated APP23 animals, treatment with bupropion reduced resting time and increased speed. On treatment with citalopram, moving and resting time were unchanged but speed decreased. Length of the path to the goal zone did not change on either bupropion or citalopram. Conclusion. Bupropion increases psychomotor activity in APP23 transgenic animals, while citalopram slightly reduces psychomotor activity. Spatial learning per se is unaffected by treatment with either bupropion or citalopram.

\section{Introduction}

Alzheimer's disease (AD) is a progressive neurodegenerative disease characterized by accruing cognitive and noncognitive deficits. Among the latter, aberrant motor behavior with either overall slowing or hyperactivity, and depression are common symptoms [1-5].

In patients with $\mathrm{AD}$, presence of apathy as indicated by decreased motor activity and decreased agitation/hyperactivity as indicated by increased motor activity is associated with faster functional and cognitive decline [57]. Levels of dopamine, noradrenaline, and serotonin are decreased in patients with $\mathrm{AD}$ [8-11]. In animal models of $\mathrm{AD}$, dopamine, noradrenaline, and serotonin all have been reported to improve cognitive functioning $[12,13]$.

Bupropion is a monoamine reuptake inhibitor selective for dopaminergic and to a lesser extent noradrenergic neurotransmission but has no effect on serotonergic neurotransmission [14]. Bupropion improved visual memory in patients with major depressive disorder [15]. In rodent animal models, bupropion significantly decreased the duration of immobility on the forced swim test [16] and increased locomotor activity in freely moving animals [17].

Citalopram is a potent selective inhibitor of serotonin reuptake [18] and increases extracellular serotonin concentrations in the hippocampus of rats [19] but has no effect on the uptake of noradrenaline and dopamine [20]. Citalopram was recently reported to improve spatial memory in rats [21] and to decrease immobility time in the forced swim test [22].

A standard paradigm for the assessment of cognition in animal research is the investigation of spatial learning in water and dry-land mazes [23-25]. While early work on spatial orientation in rodents was performed in complex dryland mazes [24], since the mid 1980s complex spatial tasks predominantly are assessed in water mazes [25]. However, 


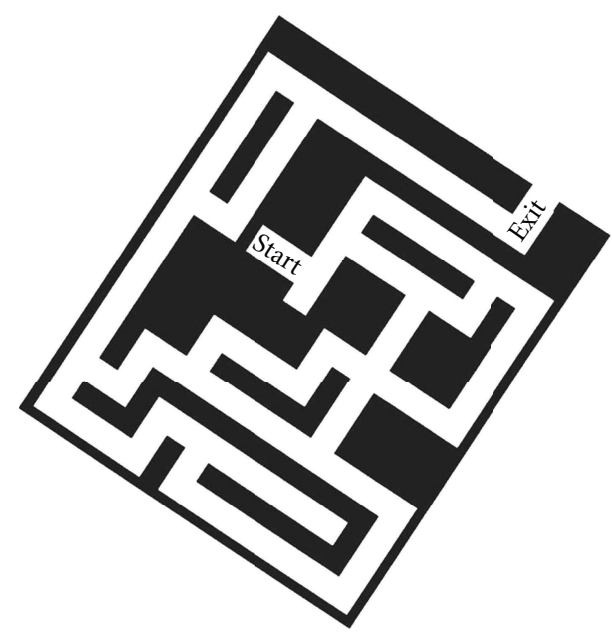

Figure 1: Aerial view of the complex maze. Animals were placed in the start zone. A video-tracking system (cf. Section 2 ) registered the location of the animals' position at a frequency of $1 \mathrm{~Hz}$.

using water mazes poses an additional stress on animals [26]. Hence, water maze learning likely not only assesses cognitive processes of spatial memory but is confounded by noncognitive components such as anxiety. It was the goal of the present study to assess whether common substances used for treatment of depression in humans affect spatial learning in a transgenic animal model of AD.

\section{Methods}

Experiments were performed under the animal protocol number 1006 (Regierungspräsidium Tübingen).

2.1. Animals and Treatment. Three groups of 4.5-month-old male APP23 mice (Charles River) and one group of same aged male wild-type mice were used in this study. Three or four animals were housed in a cage and were maintained on a $12 \mathrm{~h}$ light/dark cycle in a temperature $\left(22 \pm 2^{\circ} \mathrm{C}\right)$ and humidity $(55 \pm 5 \%)$ controlled room similar to previous protocols $[23,27,28]$.

One group of APP23 mice was treated with a daily i.p. injection of bupropion $(20 \mathrm{mg} / \mathrm{kg}$ body weight), another with citalopram (10 mg/kg body weight), respectively, starting fourteen days prior to onset of experiments. One group of APP23 mice and wild-type mice were NaCl-sham treated with the same protocol.

2.2. Maze and Behavioural Testing. To assess spatial memory, we used a complex maze that has been described previously [23] (Figure 1). Starting on the date of the last treatment, animals were trained four times a day for three consecutive days and two times on the fourth day. They had a maximum time of $300 \mathrm{~s}$ to find the exit, where they were rewarded with a food pellet. The behavioural testing took place between 11:00 AM and 5:00 PM. Different parameters, for example, duration, moving and resting time were recorded by a tracking system (Multitrack, Accuscan, USA).
2.3. Statistical Analysis. All statistical analyses were carried out using the statistics program SPSS (SPSS 17.0 for Windows, SPSS Inc. IL, Chicago, 60606). Statistical significance was accepted at $P<0.05$.

\section{Results}

3.1. Sham-Treated Groups. Both wild-type and APP23 animals improved their performance during repeated exposure to the dry-land maze as shown by a significant effect of trial on total time (two-way ANOVA; $F_{13,154}=6.751, P<0.001$ ), resting time (two-way ANOVA; $F_{13,154}=5.042, P<0.001$ ), and moving time (two-way ANOVA; $F_{13,154}=9.157, P<$ $0.001)$. Both groups increased their running speed over all trials (two-way ANOVA; $F_{13,154}=11.577, P<0.001$ ) with wild-type animals more so than APP23 animals (two-way ANOVA; $F_{1,154}=28.676, P<0.001$ ) (Figure 2(a)). To catch the efficacy of spatial learning, it is thus necessary to determine the path length for reaching the goal zone. Both wild-type and APP23 animals improved their performance during repeated exposure to the dry-land maze as shown by a significant effect of trial on distance (two-way ANOVA; $F_{13,154}=4.942, P<0.001$ ) (Figure 2(b)). Path length was shorter for wild-type animals than for APP23 animals (twoway ANOVA; $\left.F_{1,154}=37,767, P<0.001\right)$.

3.2. Antidepressant-Treated Groups. To assess the effect of treating APP23 animals, we performed a two-way ANOVA with treatment groups sham treatment, bupropion treatment, and citalopram-treatment. There was a significant effect of treatment group on total time $\left(F_{2,224}=12.794, P<\right.$ 0.001) with Fisher LSD multiple comparison testing indicating significant differences (Table 1, Figure 3). Likewise, a significant effect of treatment group was found on resting time $\left(F_{2,224}=18.103, P<0.001\right)$ with Fisher LSD multiple comparison testing indicating significant differences for treatment with bupropion but not for citalopram treatment (Table 1, Figure 3). Contrary, no overall effect of treatment was found on moving time $\left(F_{2,224}=2.224, P=0.111\right.$; Table 1, Figure 3).

Analysis of running speed featured significant treatment differences $\left(F_{2,224}=17.507, P<0.001\right)$ with Fisher LSD multiple comparison testing showing that bupropion-treated animals run faster while citalopram-treated animals run with less speed than sham-treated animals (Table 2, Figure 4(a)). Further there was no significant effect of treatment group on distance $\left(F_{2,224}=0.124, P=0.883\right)$ (Table 2, Figure 4(b)).

\section{Discussion}

Maze studies are an established means to investigate spatial learning in experimental animals [24], both in water mazes [25] and dry-land mazes [23]. Compared to wild-type animals, the total, moving, and resting time to find the goal zone were decreased in APP23 transgenic animals and the running speed was increased. However, path length was also shorter in wild-type than APP23 animals. We conclude that the difference between wild-type and APP23 animals reflects 


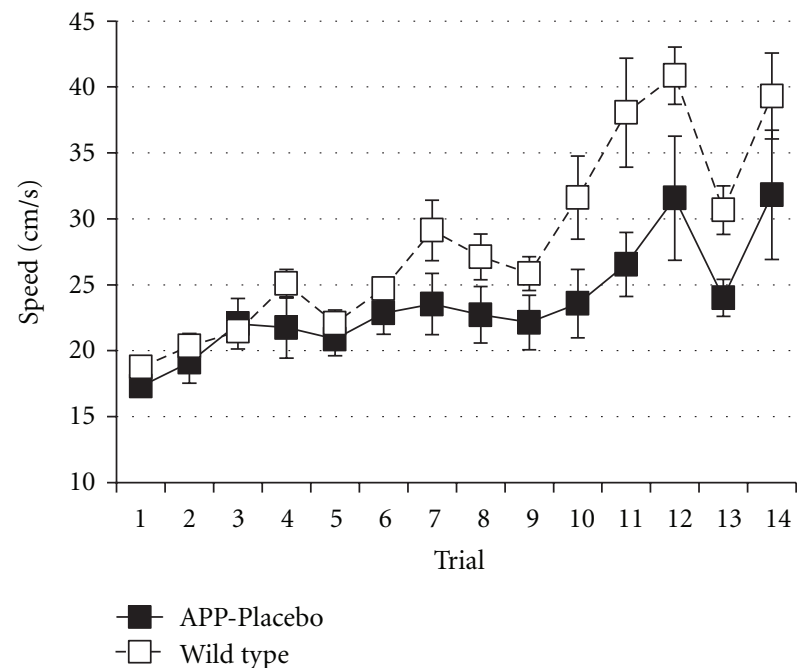

(a)

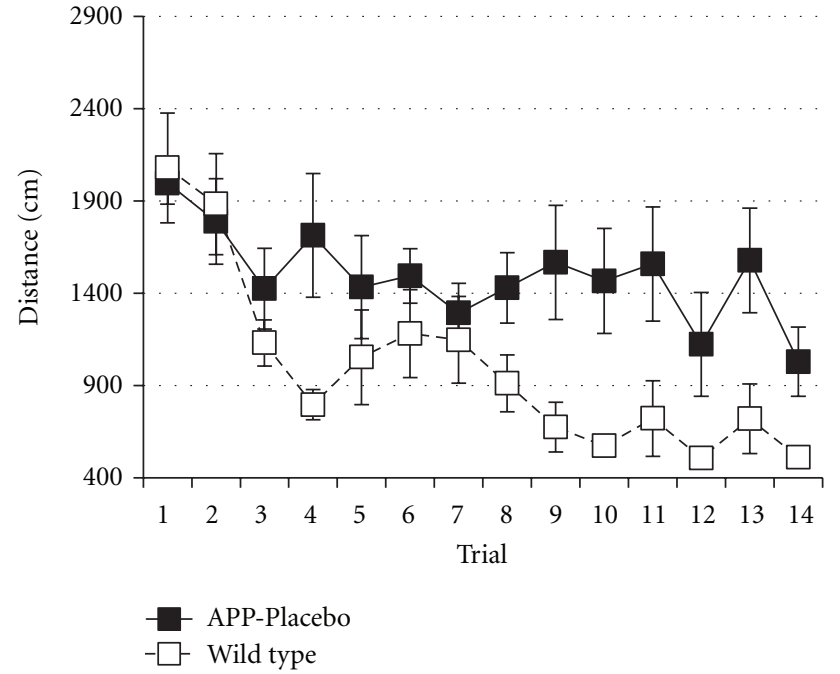

(b)

FigURE 2: Running speed (a) and learning curve for the distance (b) to escape from the complex maze. Values represent means and standard errors for a group of wild-type animals ( $n=7$, open squares) and APP23 animals ( $n=6$, filled squares), both sham treated. Values represent means \pm standard errors.

TABle 1: Two-way ANOVA for total, resting and moving time for APP23 animals with treatment groups sham treatment (sham), bupropion treatment (bup), and citalopram treatment (cit). Post hoc multiple comparison testing (Fisher LSD) with $P$ values for comparison of differences between groups. ${ }^{*}$ Indicates statistical significance.

\begin{tabular}{lcccc}
\hline & Mean & SEM & \multicolumn{2}{c}{ Between group P value } \\
& & & To sham & To bup \\
\hline $\begin{array}{l}\text { Total time } \\
\text { sham }\end{array}$ & 174.8 & 11.3 & & \\
$\quad$ bup & 116.5 & 8.8 & $<0.001^{*}$ & - \\
$\quad$ cit & 174.2 & 11.6 & 0.964 & $<0.001^{*}$ \\
$\begin{array}{l}\text { Resting time } \\
\text { sham }\end{array}$ & 104.9 & 8.1 & & \\
bup & 55.1 & 5.6 & $<0.001^{*}$ & - \\
cit & 103.8 & 8.7 & 0.912 & $<0.001^{*}$ \\
Moving time & & & & \\
sham & 69.9 & 3.7 & & - \\
bup & 61.4 & 3.7 & 0.081 & \\
cit & 70.4 & 4.0 & 0.926 & 0.066 \\
\hline
\end{tabular}

both, better spatial learning and higher psychomotor activity. This is in good harmony with previous studies showing diminished learning in middle-aged APP23 animals $[29,30]$. Reduced running speed in APP23 is in good harmony with a previous study with reduced psychomotor activity in another transgenic mouse model of AD, the APP/PS1 transgenic model [31].

Citalopram has been used in dosages from $0.01 \mathrm{mg} / \mathrm{kg}$ to $8 \mathrm{mg} / \mathrm{kg}$. The effects on spatial cognition remain ambiguous
TABLE 2: Two-way ANOVA for running speed and distance for APP23 animals with treatment groups sham treatment (sham), bupropion treatment (bup), and citalopram treatment (cit). Post hoc multiple comparison testing (Fisher LSD) with $P$ values for comparison of differences between groups. ${ }^{*}$ Indicates statistical significance.

\begin{tabular}{lcccc}
\hline & Mean & SEM & \multicolumn{2}{c}{ Between group P value } \\
& & & To sham & To bup \\
\hline $\begin{array}{l}\text { Running speed } \\
\text { sham }\end{array}$ & 23.6 & 0.8 & & \\
$\quad$ bup & 25.8 & 0.7 & $0.003^{*}$ & - \\
$\quad$ cit & 21.5 & 0.6 & $0.006^{*}$ & $<0.001^{*}$ \\
$\begin{array}{l}\text { Distance } \\
\text { sham }\end{array}$ & 1492.2 & 66.2 & & \\
bup & 1441.5 & 82.3 & 0.642 & - \\
cit & 1447.4 & 84.0 & 0.693 & 0.957 \\
\hline
\end{tabular}

and depend on dosage, paradigm, species, and the interaction thereof. At low dosages, citalopram did not affect spatial learning or even improved it [21] but had negative effects in dosages higher than $4 \mathrm{mg} / \mathrm{kg}$ in rats [32]. At moderate dosages of about $5 \mathrm{mg} / \mathrm{kg}$, citalopram decreased immobility time in the forced swim test [22]. To our knowledge, the present study is the first to address the effects of citalopram on spatial learning in a transgenic mouse model of AD. In this model, high dosages of citalopram did not change path length, total, moving, or resting time, while running speed was slightly decreased. We interpret this such as to indicate that spatial learning per se is unaffected but that psychomotor activity is slightly decreased. This is in good harmony with previous reports showing either a slight decrease of psychomotor activity on administration 

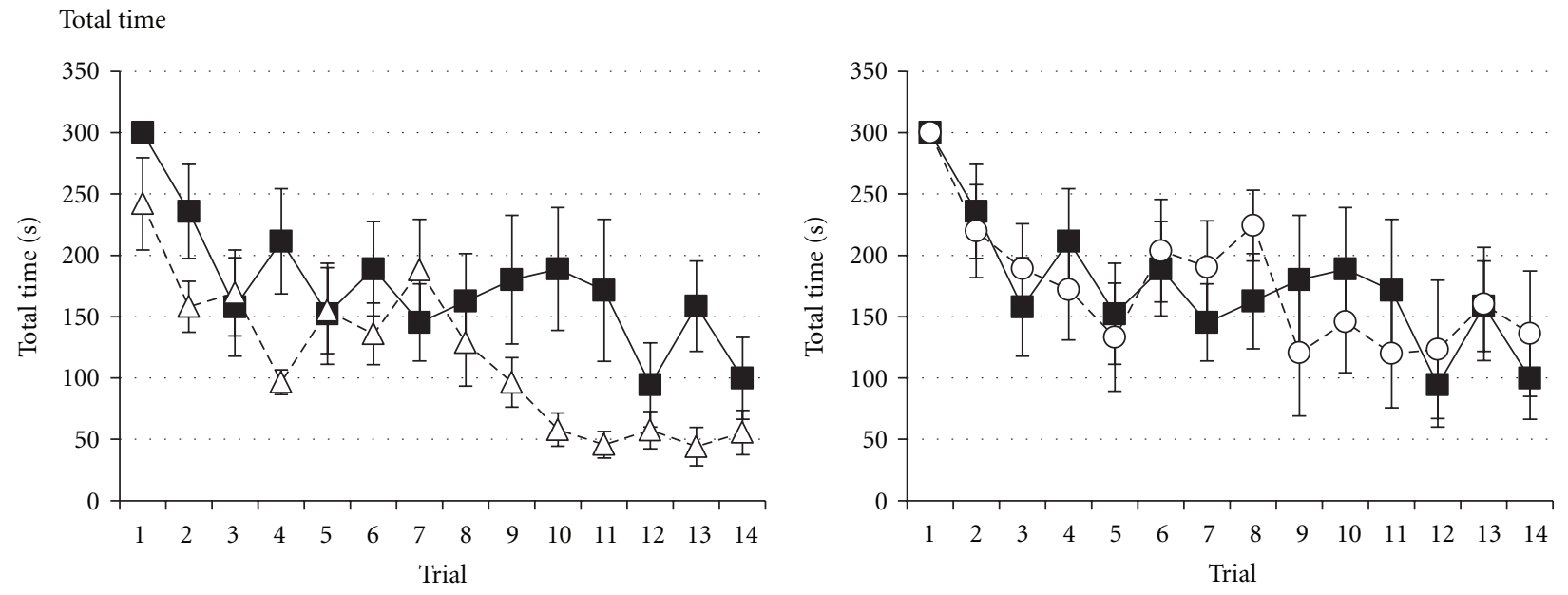

Moving time
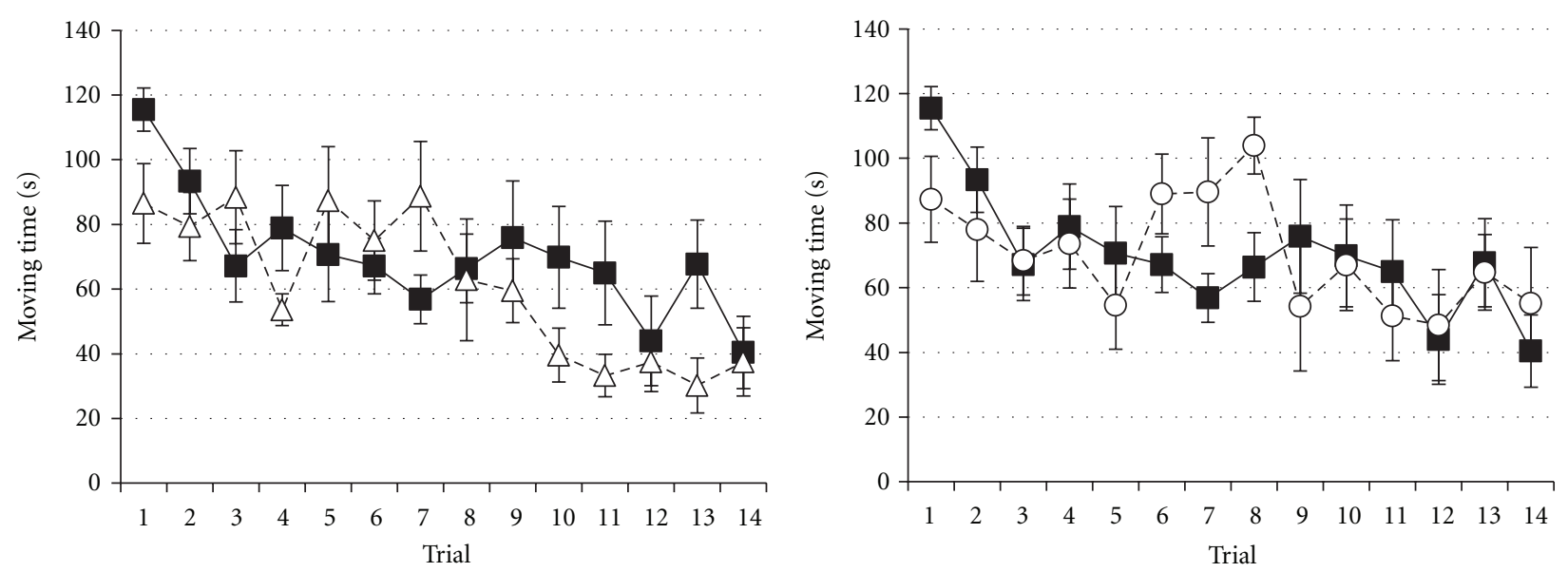

Resting time
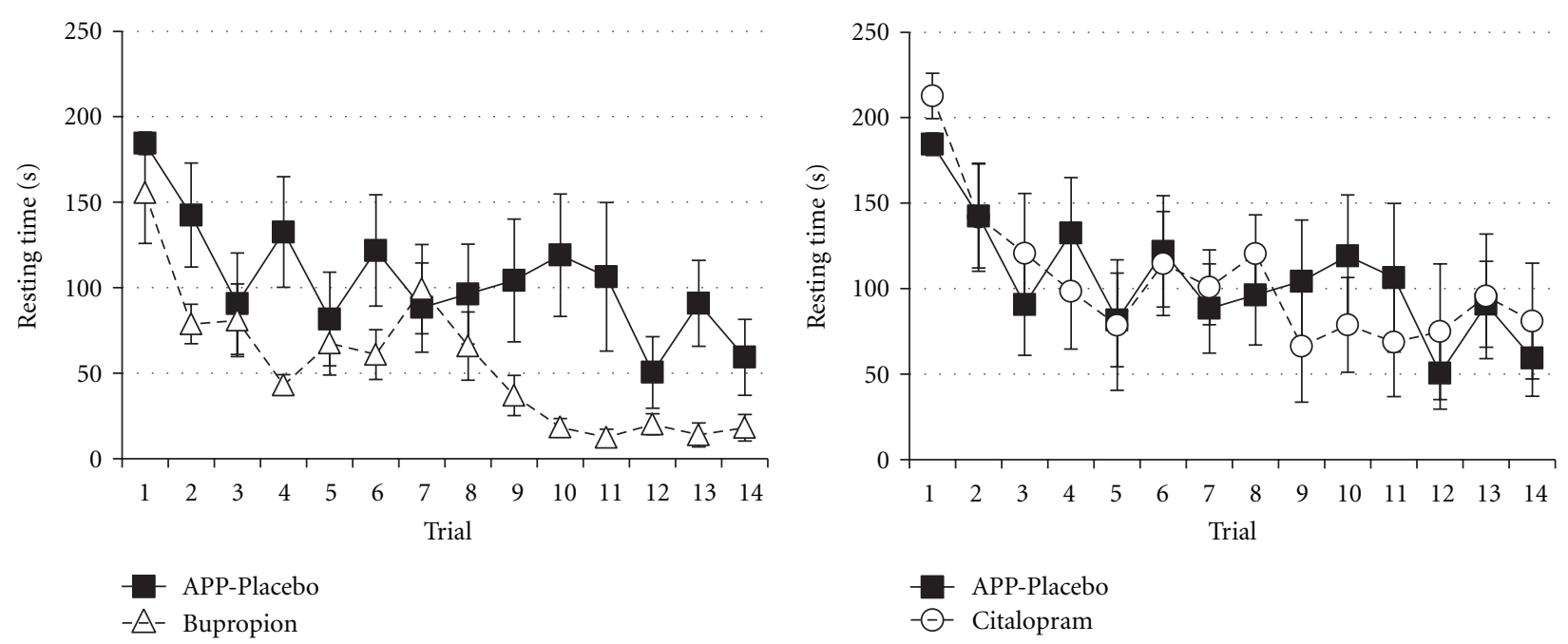

FIgURE 3: Learning curve for the time to escape from the complex maze in APP23 animals sham treated ( $n=6$, filled squares), APP23 animals treated with bupropion ( $n=7$, filled triangles), or APP23 animals treated with citalopram $(n=6$, filled circles). Values represent means \pm standard errors. 

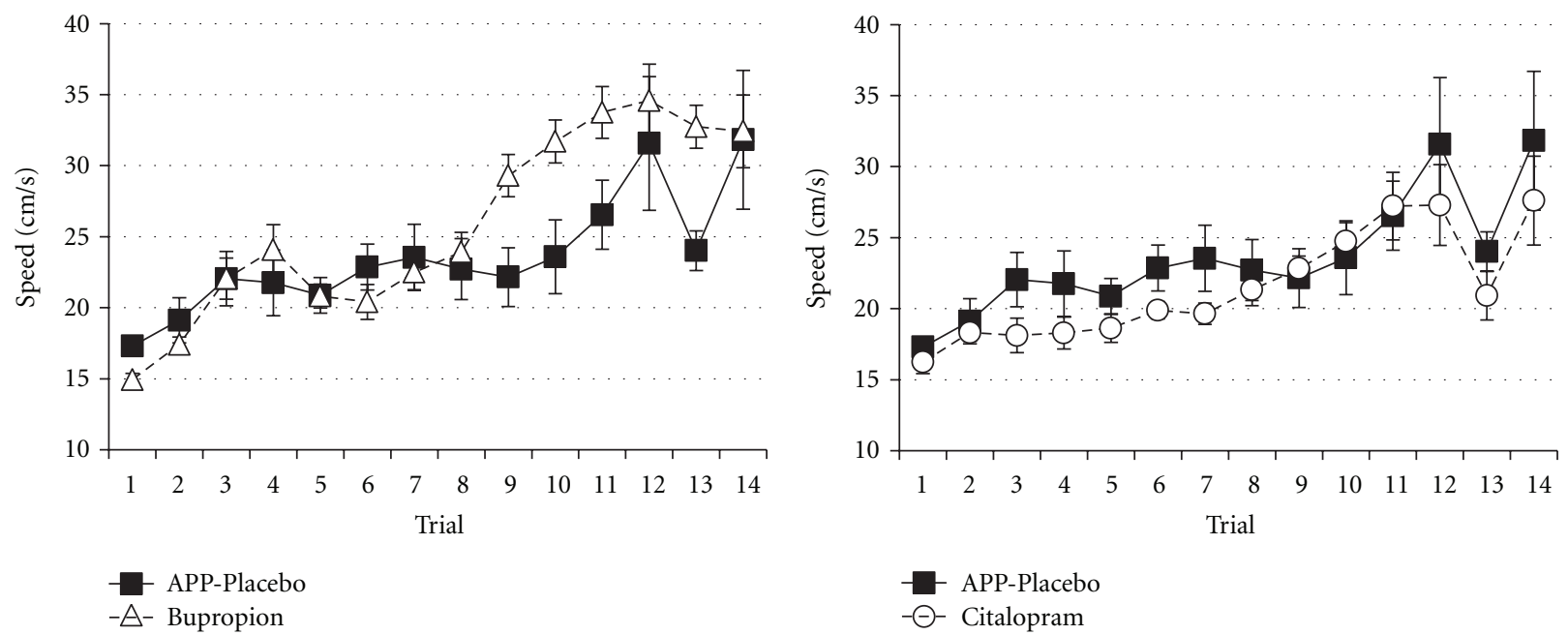

(a)
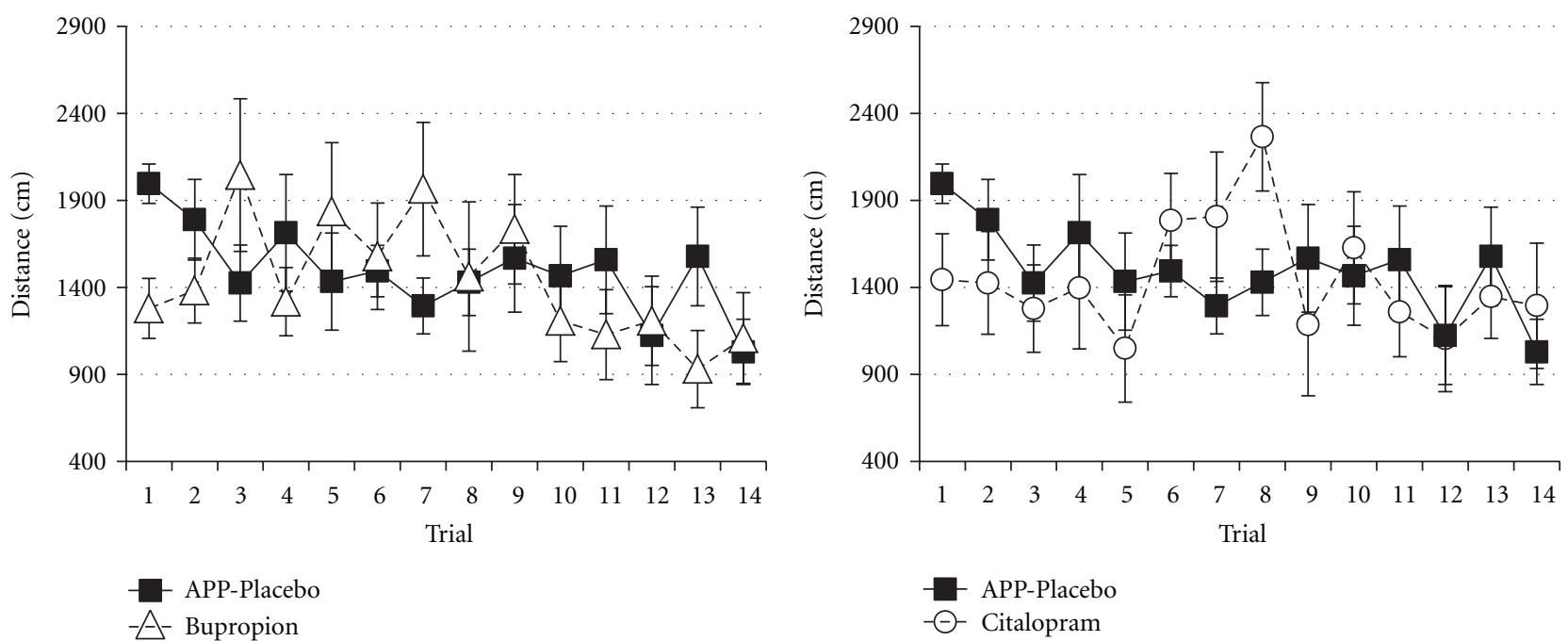

(b)

Figure 4: Running speed (a) and learning curve for distance (b) to escape from the complex maze in APP23 animals sham treated ( $n=6$, filled squares), APP23 animals treated with bupropion ( $n=7$, filled triangles), or APP23 animals treated with citalopram $(n=6$, filled circles). Values represent means \pm standard errors.

of comparable dosages of citalopram [33] or unchanged locomotor activity [34]. At least in clinical studies, no benefit on cognition was found on treating $\mathrm{AD}$ patients with citalopram $[35,36]$.

On treatment of APP23 animals with bupropion, resting time decreased and running speed increased while length of path and moving time remained unchanged. We interpret this finding such as to indicate that bupropion does not improve spatial learning per se but that it increases psychomotor activity. This is in good harmony with a previous study in mice showing an increased locomotor activity in dosages from $1 \mathrm{mg} / \mathrm{kg}$ to $20 \mathrm{mg} / \mathrm{kg}$ [37].

Altogether, bupropion and citalopram differentially affect psychomotor activity in the APP23 transgenic mouse model of $\mathrm{AD}$ while spatial learning per se is unaffected.

\section{Conflict of Interests}

K. L. Neumeister has no conflict of interests to declare; M. $\mathrm{W}$. Riepe partakes in advisory boards and is on the speaker board of pharmaceutical companies involved in research on treatments for dementia.

\section{References}

[1] J. C. Youn, D. Y. Lee, J. H. Jhoo, K. W. Kim, I. H. Choo, and J. I. Woo, "Prevalence of neuropsychiatric syndromes in Alzheimer's disease (AD)," Archives of Gerontology and Geriatrics, vol. 52, no. 3, pp. 258-263, 2011.

[2] T. C. Kuo, Y. Zhao, S. Weir, M. S. Kramer, and A. S. Ash, "Implications of comorbidity on costs for patients with alzheimer disease," Medical Care, vol. 46, no. 8, pp. 839-846, 2008. 
[3] M. Benoit, P. Staccini, P. Brocker et al., "Behavioral and psychological symptoms in Alzheimer's disease: results from REAL.FR study," Revue de Medecine Interne, vol. 24, supplement 3, pp. 319s-324s, 2003.

[4] C. G. Lyketsos, O. Lopez, B. Jones, A. L. Fitzpatrick, J. Breitner, and S. Dekosky, "Prevalence of neuropsychiatric symptoms in dementia and mild cognitive impairment: results from the cardiovascular health study," Journal of the American Medical Association, vol. 288, no. 12, pp. 1475-1483, 2002.

[5] M. Benoit, P. H. Robert, P. Staccini et al., "One-year longitudinal evaluation of neuropsychiatric symptoms in Alzheimer's disease. The REAL.FR study," Journal of Nutrition, Health and Aging, vol. 9, no. 2, pp. 95-99, 2005.

[6] L. Lechowski, M. Benoit, P. Chassagne et al., "Persistent apathy in Alzheimer's disease as an independent factor of rapid functional decline: the REAL longitudinal cohort study," International Journal of Geriatric Psychiatry, vol. 24, no. 4, pp. 341346, 2009.

[7] S. E. Starkstein, R. Jorge, R. Mizrahi, and R. G. Robinson, "A prospective longitudinal study of apathy in Alzheimer's disease," Journal of Neurology, Neurosurgery and Psychiatry, vol. 77, no. 1, pp. 8-11, 2006.

[8] B. Winblad, J. Hardy, L. Backman, and L. G. Nilsson, "Memory function and brain biochemistry in normal aging and in senile dementia," Annals of the New York Academy of Sciences, vol. 444, pp. 255-268, 1985.

[9] E. Mohr, T. Mendis, I. N. Rusk, and J. D. Grimes, "Neurotransmitter replacement therapy in Alzheimer's disease," Journal of Psychiatry and Neuroscience, vol. 19, no. 1, pp. 17-23, 1994.

[10] D. M. Mann and P. O. Yates, "Neurotransmitter deficits in Alzheimer's disease and in other dementing disorders," Human Neurobiology, vol. 5, no. 3, pp. 147-158, 1986.

[11] C. G. Gottfries, R. Adolfsson, and S. M. Aquilonius, "Biochemical changes in dementia disorders of Alzheimer type (AD/SDAT)," Neurobiology of Aging, vol. 4, no. 4, pp. 261-271, 1983.

[12] R. Ganguly and D. Guha, "Alteration of brain monoamines \& EEG wave pattern in rat model of Alzheimer's disease \& protection by Moringa oleifera," Indian Journal of Medical Research, vol. 128, no. 6, pp. 744-751, 2008.

[13] M. T. Heneka, M. Ramanathan, A. H. Jacobs et al., "Locus ceruleus degeneration promotes Alzheimer pathogenesis in amyloid precursor protein 23 transgenic mice," Journal of Neuroscience, vol. 26, no. 5, pp. 1343-1354, 2006.

[14] E. Richelson and M. Pfenning, "Blockade by antidepressants and related compounds of biogenic amine uptake into rat brain synaptosomes: most antidepressants selectively block norepinephrine uptake," European Journal of Pharmacology, vol. 104, no. 3-4, pp. 277-286, 1984.

[15] I. Herrera-Guzmán, E. Gudayol-Ferré, J. Lira-Mandujano et al., "Cognitive predictors of treatment response to bupropion and cognitive effects of bupropion in patients with major depressive disorder," Psychiatry Research, vol. 160, no. 1, pp. 72-82, 2008.

[16] Y. Kitamura, T. Yagi, K. Kitagawa et al., "Effects of bupropion on the forced swim test and release of dopamine in the nucleus accumbens in ACTH-treated rats," Naunyn-Schmiedeberg's Archives of Pharmacology, vol. 382, no. 2, pp. 151-158, 2010.

[17] N. Sidhpura, P. Redfern, H. Rowley, D. Heal, and S. Wonnacott, "Comparison of the effects of bupropion and nicotine on locomotor activation and dopamine release in vivo," Biochemical Pharmacology, vol. 74, no. 8, pp. 1292-1298, 2007.
[18] R. W. Fuller, "Serotonin uptake inhibitors: uses in clinical therapy and in laboratory research," Progress in Drug Research, vol. 45, pp. 167-204, 1995.

[19] S. Hjorth, D. Westlin, and H. J. Bengtsson, "WAY100635induced augmentation of the 5-HT-elevating action of citalopram: relative importance of the dose of the 5-HT(1A) (Auto)receptor blocker versus that of the 5-HT reuptake inhibitor," Neuropharmacology, vol. 36, no. 4-5, pp. 461-465, 1997.

[20] J. Hyttel, "Citalopram-pharmacological profile of a specific serotonin uptake inhibitor with antidepressant activity," Progress in Neuro-Psychopharmacology and Biological Psychiatry, vol. 6, no. 3, pp. 277-295, 1982.

[21] N. Egashira, Y. Matsumoto, K. Mishima et al., "Low dose citalopram reverses memory impairment and electroconvulsive shock-induced immobilization," Pharmacology Biochemistry and Behavior, vol. 83, no. 1, pp. 161-167, 2006.

[22] A. V. Kulikov, M. A. Tikhonova, D. V. Osipova, V. A. Kulikov, and N. K. Popova, "Association between tryptophan hydroxylase-2 genotype and the antidepressant effect of citalopram and paroxetine on immobility time in the forced swim test in mice," Pharmacology Biochemistry and Behavior, vol. 99, no. 4, pp. 683-687, 2011.

[23] R. Hellweg, P. Lohmann, R. Huber, A. Kühl, and M. W. Riepe, "Spatial navigation in complex and radial mazes in APP23 animals and neurotrophin signaling as a biological marker of early impairment," Learning and Memory, vol. 13, no. 1, pp. 63-71, 2006.

[24] K. S. Lashley and S. I. Franz, "The effects of cerebral destruction upon habit-formation and retention in the albino rat," Psychobiology, vol. 1, no. 2, pp. 71-139, 1912.

[25] R. G. M. Morris, "Spatial localization does not require the presence of local cues," Learning and Motivation, vol. 12, no. 2, pp. 239-260, 1981.

[26] F. E. Harrison, A. H. Hosseini, and M. P. McDonald, "Endogenous anxiety and stress responses in water maze and Barnes maze spatial memory tasks," Behavioural Brain Research, vol. 198, no. 1, pp. 247-251, 2009.

[27] C. Lange-Asschenfeldt, P. Lohmann, and M. W. Riepe, "Hippocampal synaptic depression following spatial learning in a complex maze," Experimental Neurology, vol. 203, no. 2, pp. 481-485, 2007.

[28] C. Lange-Asschenfeldt, P. Lohmann, and M. W. Riepe, "Spatial performance in a complex maze is associated with persistent long-term potentiation enhancement in mouse hippocampal slices at early training stages," Neuroscience, vol. 147, no. 2, pp. 318-324, 2007.

[29] D. Cao, H. Lu, T. L. Lewis, and N. Li, "Intake of sucrosesweetened water induces insulin resistance and exacerbates memory deficits and amyloidosis in a transgenic mouse model of Alzheimer disease," Journal of Biological Chemistry, vol. 282, no. 50, pp. 36275-36282, 2007.

[30] D. Van Dam, D. Abramowski, M. Staufenbiel, and P. P. De Deyn, "Symptomatic effect of donepezil, rivastigmine, galantamine and memantine on cognitive deficits in the APP23 model," Psychopharmacology, vol. 180, no. 1, pp. 177-190, 2005.

[31] P. L. Pugh, J. C. Richardson, S. T. Bate, N. Upton, and D. Sunter, "Non-cognitive behaviours in an APP/PS1 transgenic model of Alzheimer's disease," Behavioural Brain Research, vol. 178, no. 1, pp. 18-28, 2007.

[32] N. Majlessi and N. Naghdi, "Impaired spatial learning in the Morris water maze induced by serotonin reuptake inhibitors 
in rats," Behavioural Pharmacology, vol. 13, no. 3, pp. 237-242, 2002.

[33] B. R. Brookshire and S. R. Jones, "Direct and indirect 5-HT receptor agonists produce gender-specific effects on locomotor and vertical activities in C57 BL/6J mice," Pharmacology Biochemistry and Behavior, vol. 94, no. 1, pp. 194-203, 2009.

[34] M. Brocco, A. Dekeyne, S. Veiga, S. Girardon, and M. J. Millan, "Induction of hyperlocomotion in mice exposed to a novel environment by inhibition of serotonin reuptake: a pharmacological characterization of diverse classes of antidepressant agents," Pharmacology Biochemistry and Behavior, vol. 71, no. 4, pp. 667-680, 2002.

[35] A. L. Nyth and C. G. Gottfries, "The clinical efficacy of citalopram in treatment of emotional disturbances in dementia disorders. A Nordic multicentre study," British Journal of Psychiatry, vol. 157, pp. 894-901, 1990.

[36] J. Caballero, M. Hitchcock, D. Beversdorf, D. Scharre, and M. Nahata, "Long-term effects of antidepressants on cognition in patients with Alzheimer's disease," Journal of Clinical Pharmacy and Therapeutics, vol. 31, no. 6, pp. 593-598, 2006.

[37] A. S. Rauhut, M. Hawrylak, and S. K. Mardekian, "Bupropion differentially alters the aversive, locomotor and rewarding properties of nicotine in CD-1 mice," Pharmacology Biochemistry and Behavior, vol. 90, no. 4, pp. 598-607, 2008. 


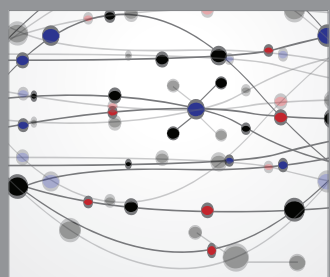

The Scientific World Journal
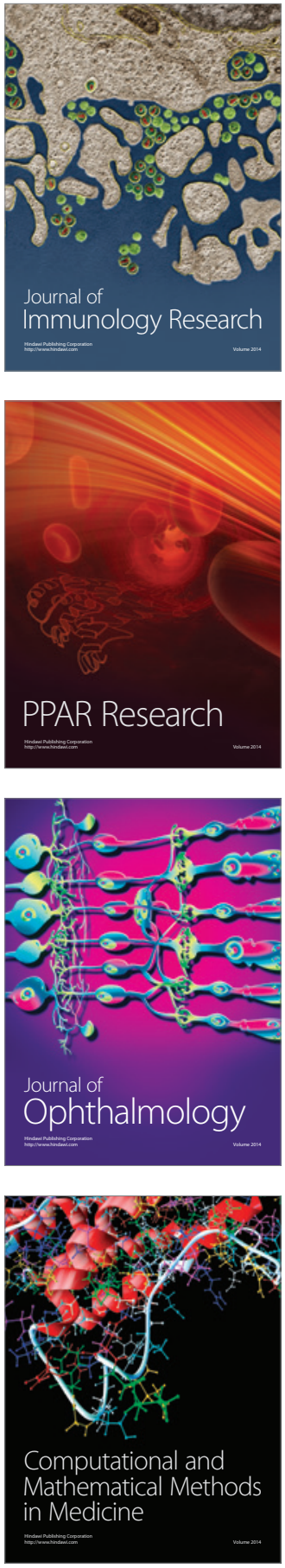

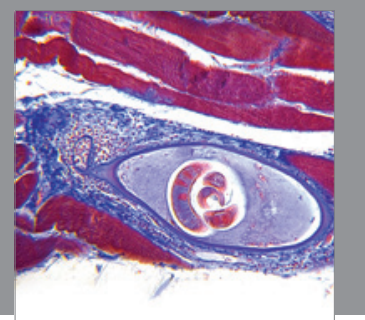

Gastroenterology

Research and Practice
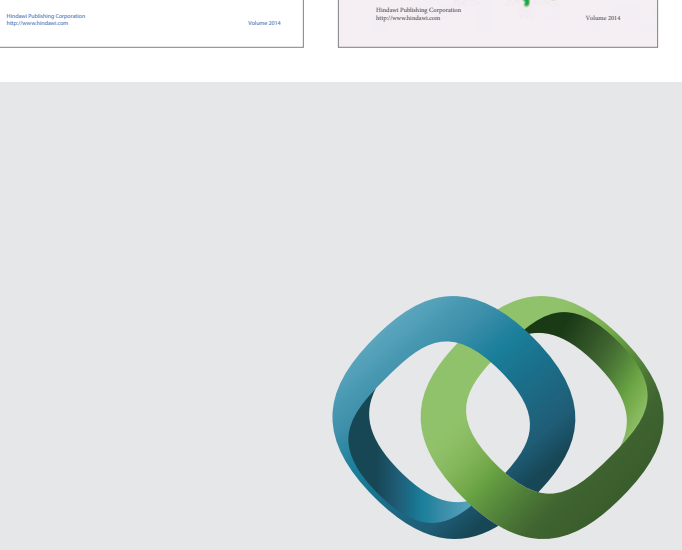

\section{Hindawi}

Submit your manuscripts at

http://www.hindawi.com
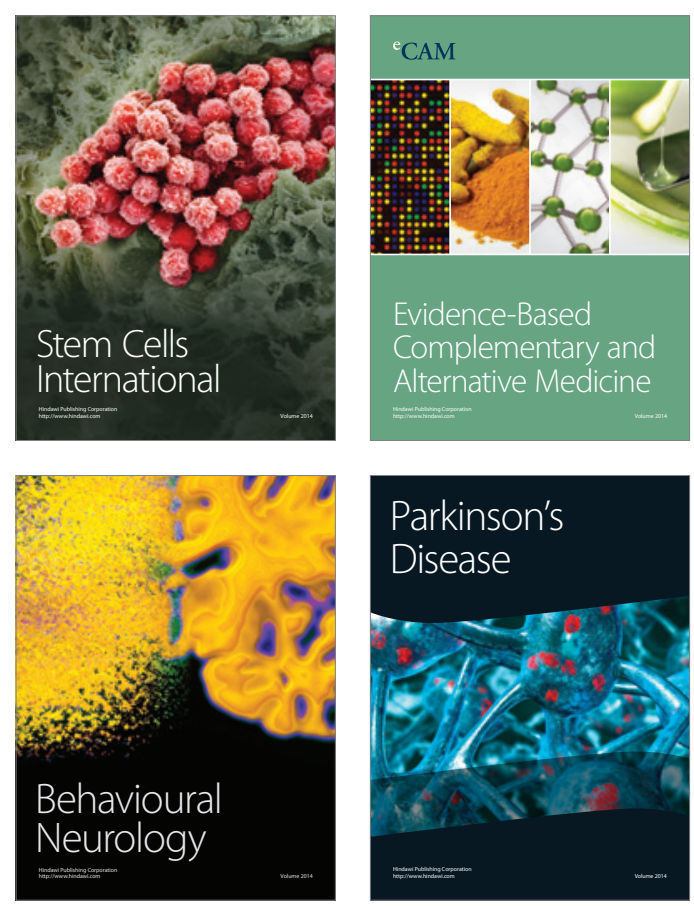

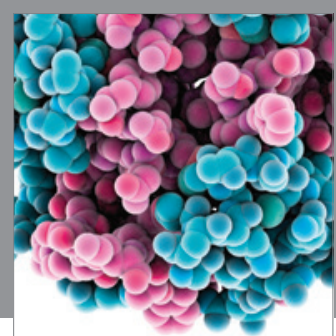

Journal of
Diabetes Research

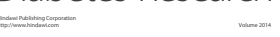

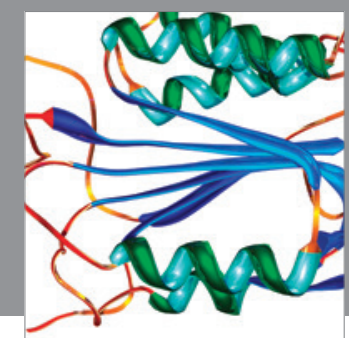

Disease Markers
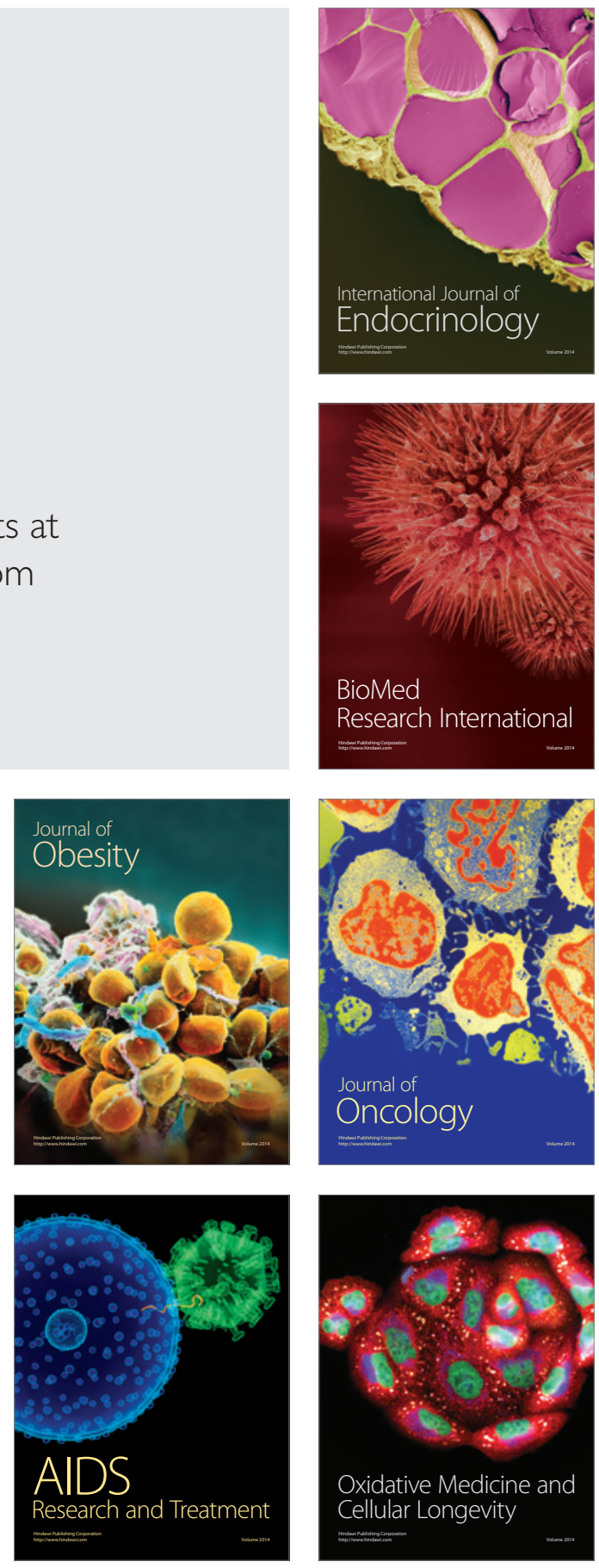